Research Article

\title{
Mathematical Formulation of Feedback Linearizing Control of Doubly Fed Induction Generator Including Magnetic Saturation Effects
}

\author{
Julia Tholath Jose (iD) and Adhir Baran Chattopadhyay \\ BITS Pilani-Dubai Campus, P.O.Box 345055, Dubai International Academic City, Dubai, UAE \\ Correspondence should be addressed to Julia Tholath Jose; p20140003@dubai.bits-pilani.ac.in
}

Received 12 June 2019; Revised 1 October 2019; Accepted 13 November 2019; Published 1 February 2020

Academic Editor: Juan P. Amezquita-Sanchez

Copyright (c) 2020 Julia Tholath Jose and Adhir Baran Chattopadhyay. This is an open access article distributed under the Creative Commons Attribution License, which permits unrestricted use, distribution, and reproduction in any medium, provided the original work is properly cited.

\begin{abstract}
This paper proposes a control methodology based on feedback linearization for a doubly fed induction generator (DFIG) incorporating the magnetic saturation. The feedback linearization algebraically converts a nonlinear system model into a linear model, allowing the use of linear control techniques. Feedback linearization control depends on the model of the system and is therefore sensitive to parameter variations. The doubly fed induction generator (DFIG) operating under the magnetic saturation conditions results in the nonlinear variation of magnetizing inductance, which affects the performance of the control algorithm. From this stand point, on the basis of the dynamic model of the doubly fed induction generator considering magnetic saturation, the feedback linearizing control technique has been formulated. The mathematical model of the doubly fed induction generator, integrating the magnetic saturation has been formulated in the stator flux-oriented reference frame with rotor current and stator magnetizing current as state variables. Simulation studies demonstrate that the inclusion of magnetic saturation in the feedback linearization control of the doubly fed induction generator model increases its accuracy and results in a more efficient and reliable synthesis of the control algorithm.
\end{abstract}

\section{Introduction}

Doubly fed induction generator-based wind turbines are widely employed in wind energy conversion systems due to its advantages of variable speed operation, decoupled active and reactive power control, low power converters, and reduced power loss [1]. Several control techniques have been suggested by researchers for the control of DFIG-based wind turbines. Field-oriented vector control is one of the common and simple control schemes. The conventional field-oriented control realizes the decoupled control of active and reactive power by regulating the $d$-axis and $q$-axis rotor currents in the reference frame oriented along the stator flux [2]. However, field-oriented control requires tuning of multiple PI controllers and hence stability at all operating conditions cannot be assured [3]. Moreover, the doubly fed induction generator (DFIG) is a nonlinear multiple-input multiple- output system with strongly coupled variables, and the behavior of DFIG is nonlinear due to its variable rotor speed. Nonlinear controllers can completely solve this structural nonlinearity [4]. Hence, nonlinear control techniques are preferred in the high-performance control of the DFIG in the steady state and also during the start flux transients.

There has been a considerable advancement in the theory of nonlinear control over the last several decades. Among the various methods developed, one of the important nonlinear control techniques is feedback linearization $[5,6]$. In recent years, it has attracted a lot of research. The principle of feedback linearization is to convert a nonlinear system to a linear system by means of static state feedback, design a linear controller, and use the inverse transformation to get the controller for the actual nonlinear system. The main idea is to algebraically transform the dynamics of nonlinear systems into linear ones (full or partly) in order to apply 
linear control methods. This method differs from the conventional method of Jacobian linearization, as feedback linearization is obtained through state transformation and feedback methods instead of linear dynamic approximations. For nonlinear systems whose operation exists in the neighborhood of a fixed or slowly varying equilibrium, Jacobian linearization is satisfactory but it is otherwise inappropriate. It is possible to linearize and decouple systems with multiple inputs and multiple outputs by feedback linearization, thereby, enabling the efficient control of the system with linear controllers.

The feedback linearization control (FBLC) is widely used as a nonlinear control strategy in power electronics and drives [7-9]. It has been implemented in excitation controllers of synchronous generators [10-12] and also in control inputs for voltage source inverters in renewable power application [13-16]. The methodology of feedback linearization has been used to linearize and decouple the control of induction motor. The necessity of keeping the flux constant can be avoided by the application of the inputoutput linearization controller in induction motors. In the input-output linearization control, the coordinates of fieldoriented control are changed to a new coordinate system and by applying state feedback it is possible to decouple the speed control from the flux control [17-19]. In [20], a feedback linearization control algorithm with a sliding mode observer has been implemented for the direct torque control of the induction motor.

Several research studies have already been carried out in the area of control of the doubly fed induction generator using feedback linearization strategy. An input-output feedback linearization of the doubly fed induction generator with rotor angle and stator flux as output variables has been implemented, and Kalman filter as a disturbance observer is added to track desired outputs [3]. In [21], the feedback linearization method for active and reactive power control of the DFIG has been discussed. The feedback linearization controller based on the mathematical model of the DFIG with stator magnetization current has been developed and control of active and reactive power has been established [22]. The feedback linearization controller for maximum power point tracking of the DC-based doubly fed induction generator has been developed in [23]. A sliding mode control based on feedback linearization for mitigating subsynchronous resonance has been established in [24]. A state feedback linearization control technique with rotor and grid $d$ and $q$ voltages to limit the rotor over currents during three phase fault has been developed [25].

Feedback linearization control strategy is based on the model of the system and is implemented to convert the nonlinear models into linear ones by considering their states. Hence, this type of control requires the correct dynamic model knowledge as well as parameters of the mathematical model. The imprecise modeling of the controlled plant can make the performance based on feedback linearization much worse than those that can be achieved with other less sophisticated techniques. In such conditions, magnetic saturation which is not accounted in the conventional machine model can be significant. Under magnetic saturation, the inductances of the wound rotor machine model vary with the magnetization level of the machine in a nonlinear manner and also lead to new terms in the dynamic model that are not present in the classic model. This results in the increase of the nonlinearity of the model. From this stand point, the dynamic model of the machine incorporating the magnetic saturation is relevant in the formulation of feedback linearization control technique.

Although considerable research has been carried out in the area of feedback linearization control of saturated induction motor, but the feedback linearization control of the saturated doubly fed induction generator has yet to be explored. Nonlinear tracking control of a saturated induction motor using voltage input-output linearization technique is suggested in [26]. It is notable that exact linearization and decoupling of flux and speed is possible during the field weakening mode [26]. In [27], input-output linearization control of an induction motor in which magnetic saturation is incorporated by means of nonlinear magnetizing characteristics of the ferromagnetic core and is employed in the control, the observer of the state variables, and in the load torque estimator. Feedback input-output linearization control strategies for saturated induction motors have been formulated in a fixed stator frame [28]. The model of saturated induction motor with the input-output linearizing controller has been established by formulating the state space equations considering magnetic saturation along the rotor flux-oriented reference frame [29].

This paper suggests a feedback linearization technique for doubly fed induction generator, considering the effect of magnetic saturation. From this point of view, taking into account the magnetic saturation inspired by ([30], Ch 6), the complete set of equations of the dynamic state space model of the DFIG has been formulated with the rotor current and the stator magnetizing current as state variables. The nonlinear DFIG model usually considered for dynamic analysis is fourth order with stator flux, rotor flux, or any other fluxdependent state as the state variables. The DFIG model obtained after feedback linearization is second order, with only $d$ - and $q$-axis rotor currents as state variables. This results in the simplified design of the controller that is easy to implement and also in automatic elimination of the requirement for feedforward compensation. It is found that feedback linearization controllers can track the rotor current and speed references quickly.

\section{Input-Output Feedback Linearization}

The control method based on input-output feedback linearization is explained by Isidori in [6]. by

Consider a multiinput-multioutput system represented

$$
\begin{aligned}
& \dot{x}=f(x)+g \cdot u, \\
& y=h(x),
\end{aligned}
$$

where $x$ is the state space vector; $u$ is the control input; $y$ is the system output; $f$ and $g$ are smooth vector fields; and $h$ is smooth scalar function. 
The system can be input-output linearized by differentiating the output till the input appears:

$$
\dot{y}=L_{f} h(x)+L_{g} h(x) u,
$$

where $L_{f} h(x)=(\partial h / \partial x) h(x)$ and $L_{g} h(x)=(\partial h / \partial x) g(x)$, represent Lie derivatives of $h(x)$ and $g(x)$ with respect to, respectively. If $L_{g} h(x) u=0$, the output is differentiated again:

$$
y^{r}=L_{f}^{r} h(x)+L_{g}^{r-1} h(x) .
$$

If the above procedure is repeated for all inputs, the resulting $m$ equations obtained can be written as follows:

$$
\left[\begin{array}{c}
y_{1}^{\left(r_{i}\right)} \\
\vdots \\
y_{m}^{\left(r_{m}\right)}
\end{array}\right]=A(x)+E(x)\left[\begin{array}{c}
u_{1} \\
\vdots \\
u_{m}
\end{array}\right],
$$

where $E(x)$ is defined as follows:

$$
\begin{aligned}
& E(x)=\left[\begin{array}{ccc}
L_{g_{1}} L_{f}^{r_{i}-1} h_{1} & \cdots & L_{g_{m}} L_{f}^{r_{i}-1} h_{1} \\
\vdots & \ddots & \vdots \\
L_{g_{m}} L_{f}^{r_{m}-1} h_{m} & \cdots & L_{g_{m}} L_{f}^{r_{m}-1} h_{m}
\end{array}\right], \\
& A(x)=\left[\begin{array}{c}
L_{f}^{r_{i}} h_{1}(x) \\
\vdots \\
L_{f}^{r_{m}} h_{m}(x)
\end{array}\right] .
\end{aligned}
$$

The matrix $E(x)$ is called the decoupling matrix and for the system. If $E(x)$ is a nonsingular matrix, the original input $u$ is controlled by the coordinate transformation:

$$
u=-E^{-1}(x) A(x)+E^{-1}(x) v .
$$

Then, we obtain a linear relationship between output $y$ and input $v$ :

$$
\left[\begin{array}{c}
y_{1}^{\left(r_{i}\right)} \\
\vdots \\
y_{m}^{\left(r_{m}\right)}
\end{array}\right]=\left[\begin{array}{c}
v_{1} \\
\vdots \\
v_{m}
\end{array}\right]
$$

\section{System Configuration of the DFIG}

The schematic diagram of the doubly fed induction generator is shown in Figure 1. The system consists of wind turbine connected to the doubly fed induction generator. The stator of the doubly fed induction generator is directly connected to grid of constant voltage and frequency while the rotor is connected to three phase voltage of variable voltage and frequency through a back to back converter $[1,2]$.

In Figure $1, P_{s}$ and $Q_{s}$ and $P_{r}$ and $Q_{r}$ represent the active and reactive power of the stator and rotor, respectively. Furthermore, $P_{\mathrm{GSC}}$ and $Q_{\mathrm{GSC}}$ represent the power transferred to the grid through the grid side converter.

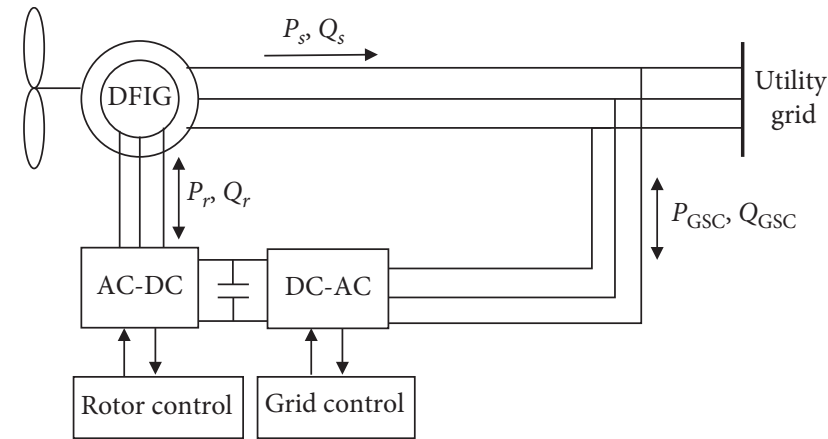

FIgURE 1: Schematic diagram of the doubly fed induction generator.

\section{Mathematical Model of the DFIG Including the Effect of Saturation}

Numerous research studies have been carried out in the field of feedback linearization control of induction machines including the effects of saturation. This paper uses the methodology prescribed for the induction motor in ([30], Sec. 6.1.1.1) to model the effect of saturation. Based on this methodology, a state space form of the doubly fed induction generator is derived that is used for formulating the feedback linearization method. The state space model of the DFIG with stator magnetizing currents and rotor currents as state variables is obtained in a reference frame oriented along the stator flux and rotating at a speed of $\omega_{m s}$. The relationship between the stationary reference frame and the reference frame oriented along the stator flux linkage space phasor is shown in Figure 2.

4.1. Stator Voltage Equations. The stator voltage equations of the doubly fed induction generator expressed in the stator flux-oriented reference frame are expressed as follows:

$$
\bar{u}_{s, \psi s}=R_{s} \bar{i}_{s, \psi s}+\frac{\mathrm{d} \bar{\psi}_{s, \psi s}}{\mathrm{~d} t}+j \omega_{m s} \bar{\psi}_{s, \psi s} .
$$

The stator flux expressed in the stator flux-oriented reference frame can be defined as follows:

$$
\bar{\psi}_{s, \psi s}=L_{m}\left|\bar{i}_{m s}\right|=\psi_{s x}+j \psi_{s y}, \quad \psi_{s y}=0 .
$$

From equations (8) and (9), stator voltage can be expressed as follows:

$$
\bar{u}_{s, \psi s}=R_{s} \bar{i}_{s, \psi s}+\frac{\mathrm{d}\left(L_{m}\left|\bar{i}_{m s}\right|\right)}{\mathrm{d} t}+j \omega_{m s} L_{m}\left|\bar{i}_{m s}\right| .
$$

In the case of a doubly fed induction generator, $\bar{i}_{s, \psi s}$ is expressed in terms of $\left|\bar{i}_{m s}\right|$ and $\bar{i}_{r, \psi s}$ :

$$
\bar{i}_{s, \psi s}=\frac{L_{m}}{L_{s}}\left(\left|\bar{i}_{m s}\right|-\bar{i}_{r, \psi s}\right),
$$

and when this is substituted in equation (10), 


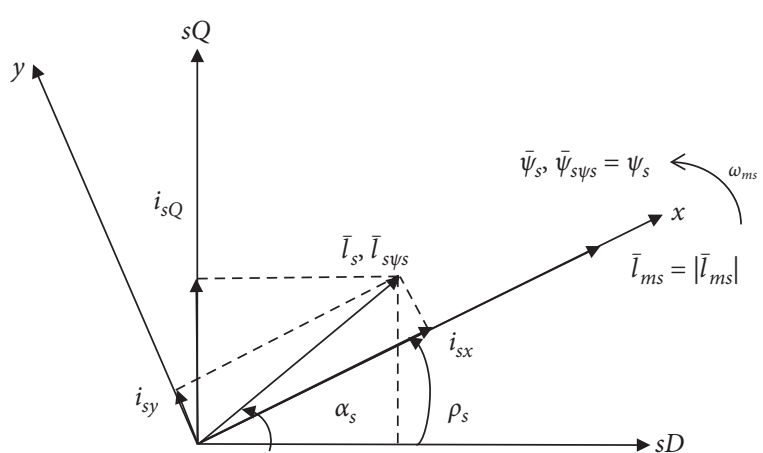

Figure 2: Space vector diagram showing stator flux linkage and stator magnetizing current space phasors.

$$
\bar{u}_{s, \psi s}=\frac{R_{s} L_{m}}{L_{s}}\left(\left|\bar{i}_{m s}\right|-\bar{i}_{r, \psi s}\right)+\frac{\mathrm{d}\left(L_{m}\left|\bar{i}_{m s}\right|\right)}{\mathrm{d} t}+j \omega_{m s} L_{m}\left|\bar{i}_{m s}\right| .
$$

In equation (12), the derivative of $\mathrm{d}\left(L_{m}\left|\bar{i}_{m s}\right|\right) / \mathrm{d} t$ is present. As magnetic saturation is considered, the magnetizing inductance varies nonlinearly with magnetizing flux linkage and magnetizing current. Hence, the derivative of nonlinear element $L_{m}$ can be expressed as follows:

$$
\frac{\mathrm{d}\left(L_{m}\left|i_{m s}\right|\right)}{\mathrm{d} t}=\frac{\mathrm{d}\left|\bar{\psi}_{s}\right|}{d\left|i_{m s}\right|} \times \frac{\mathrm{d}\left|i_{m s}\right|}{\mathrm{d} t}=L \frac{\mathrm{d}\left|i_{m s}\right|}{\mathrm{d} t}
$$

where $L=\mathrm{d}\left|\bar{\psi}_{s}\right| / \mathrm{d}\left|i_{m s}\right|$ which represents the slope of magnetization characteristics.

Substitution of equation (13) in equation (12) yields

$$
T_{s}^{*} \frac{\mathrm{d}\left|i_{m s}\right|}{\mathrm{d} t}=\frac{T_{s}}{L_{m}} u_{s, \psi s}-\left|i_{m s}\right|+\bar{i}_{r, \psi s}-j \omega_{m s} L_{m}\left|\bar{i}_{m s}\right| T_{s}
$$

where $T_{s}=L_{s} / R_{s}$ is the stator time constant and under magnetic saturation conditions modified stator time constant is $T_{s}^{*}=T_{s}\left(L / L_{m}\right)$

4.2. Rotor Voltage Equations. The relationship between the rotor current space phasor and stator magnetizing current space phasor is shown in Figure 3.

The rotor voltage equations can be expressed in the stator flux-oriented reference frame as follows:

$$
\begin{aligned}
u_{r, \psi s}= & R_{r} \bar{i}_{r, \psi s}+\frac{\mathrm{d}}{\mathrm{d} t}\left(L_{r} \bar{i}_{r, \psi s}\right)+\frac{\mathrm{d}}{\mathrm{d} t}\left(L_{m} \bar{i}_{s, \psi s}\right) \\
& +j\left(\omega_{m s}-\omega_{r}\right)\left(L_{r} \bar{i}_{r, \psi s}+L_{m} \bar{i}_{s, \psi s}\right) .
\end{aligned}
$$

However,

$$
\begin{aligned}
\frac{\mathrm{d}}{\mathrm{d} t}\left(L_{r} \bar{i}_{r, \psi s}\right)+\frac{\mathrm{d}}{\mathrm{d} t}\left(L_{m} \bar{i}_{s, \psi s}\right)= & L_{r}^{\prime} \frac{\mathrm{d} \bar{i}_{r, \psi s}}{\mathrm{~d} t}+\bar{i}_{r, \psi s} \frac{\mathrm{d} L_{m}}{\mathrm{~d} t}\left(\frac{L_{r l}}{L_{m}}\right)^{2} \\
& +\frac{\mathrm{d}}{\mathrm{d} t}\left(\frac{L_{m}^{2}}{L_{s}}\left(\left|i_{m s}\right|\right)\right),
\end{aligned}
$$

where $L_{r}^{\prime}=L_{r}-L_{m}^{2} / L_{s}$ is the rotor transient inductance.

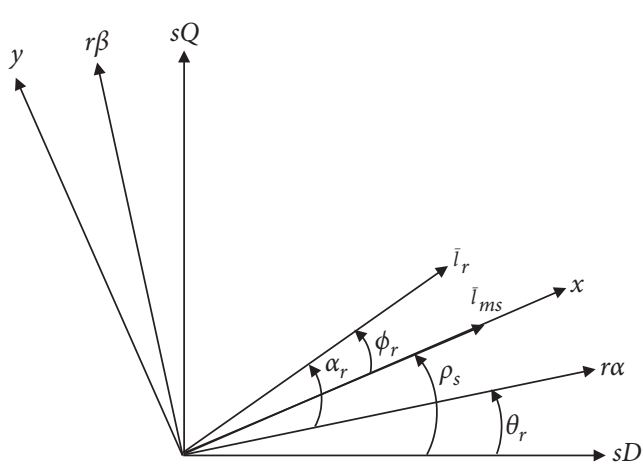

FIgURE 3: Stator magnetizing current space phasor and rotor current phasor.

Using equations (15) and (16),

$$
\begin{aligned}
& u_{r, \psi s}= R_{r} \bar{i}_{r, \psi s}+L_{r}^{\prime} \frac{\mathrm{d} \bar{i}_{r, \psi s}}{\mathrm{~d} t}+\bar{i}_{r, \psi s} \frac{\mathrm{d} L_{m}}{\mathrm{~d} t}\left(\frac{L_{r l}}{L_{m}}\right)^{2} \\
&+\frac{\mathrm{d}}{\mathrm{d} t}\left(\frac{L_{m}^{2}}{L_{s}}\left(\left|i_{m s}\right|\right)\right)+j\left(\omega_{m s}-\omega_{r}\right)\left(L_{r} \bar{i}_{r, \psi s}+L_{m} \bar{i}_{s, \psi s}\right) \\
& \frac{\mathrm{d}}{\mathrm{d} t}\left(\frac{L_{m}^{2}}{L_{s}}\left(\left|i_{m s}\right|\right)\right)=\frac{L_{m}^{2}}{L_{s}} \frac{\mathrm{d}\left|\bar{i}_{m s}\right|}{\mathrm{d} t}+\left|\bar{i}_{m s}\right| \frac{\mathrm{d} L_{m}}{\mathrm{~d} t}\left(1-\frac{L_{s l}^{2}}{L_{m}^{2}}\right) \\
& \frac{\mathrm{d} L_{m}}{\mathrm{~d} t}=\frac{\mathrm{d} L_{m}}{\mathrm{~d}\left|\bar{i}_{m s}\right|} \frac{\mathrm{d}\left|\bar{i}_{m s}\right|}{\mathrm{d} t}=\frac{L-L_{m}}{\left|\bar{i}_{m s}\right|} \frac{\mathrm{d}\left|\bar{i}_{m s}\right|}{\mathrm{d} t}
\end{aligned}
$$

where $L=\mathrm{d}\left|\psi_{s}\right| / \mathrm{d}\left|\bar{i}_{m s}\right|$ and $L_{m}=\left|\psi_{s}\right| /\left|\bar{i}_{m s}\right|, L$ is dynamic (tangent slope or incremental) inductance and it is equal to the derivative of the modulus of the stator flux-linkage space phasor with respect to the modulus of stator magnetizing current and $L_{m}$ is the static chord inductance.

Substituting (19) in (18) and then in (15), rotor voltage is expressed as follows:

$$
\begin{aligned}
u_{r, \psi s}= & R_{r} \bar{i}_{r, \psi s}+L_{r}^{\prime} \frac{\mathrm{d} \bar{i}_{r, \psi s}}{\mathrm{~d} t}+\bar{i}_{r, \psi s} \frac{L-L_{m}}{\left|\bar{i}_{m s}\right|} \frac{\mathrm{d}\left|\bar{i}_{m s}\right|}{\mathrm{d} t}\left(\frac{L_{r l}}{L_{m}}\right)^{2} \\
& +\frac{L_{m}^{2}}{L_{s}} \frac{\mathrm{d}\left|\bar{i}_{m s}\right|}{\mathrm{d} t}+\left(L-L_{m}\right)\left(1-\frac{L_{s l}^{2}}{L_{m}^{2}}\right) \frac{\mathrm{d}\left|\bar{i}_{m s}\right|}{\mathrm{d} t} \\
& +j\left(\omega_{m s}-\omega_{r}\right)\left(L_{r} \bar{i}_{r, \psi s}+L_{m} \bar{i}_{s, \psi s}\right) .
\end{aligned}
$$

From (9),

$$
\frac{\mathrm{d} i_{m s}}{\mathrm{~d} t}=\frac{\bar{u}_{s, \psi s}}{L}+\frac{R_{s} L_{m}}{L L_{s}}\left(\bar{i}_{r, \psi s}-\left|\bar{i}_{m s}\right|\right)-j \omega_{m} \frac{L_{m}}{L}\left|\bar{i}_{m s}\right| .
$$

Assume $T_{s}=L_{s} / R_{s}$ and $T_{s}^{*}=T_{s}\left(L / L_{m}\right)$ and $\Delta L=L-L_{m}$ and $\Delta L^{*}=\Delta L\left(L_{s l}^{2} / L_{s}^{2}\right)$ :

$$
\frac{\mathrm{d} i_{m s}}{\mathrm{~d} t}=\frac{\bar{u}_{s, \psi s}}{L}+\frac{1}{T_{s}^{*}} \bar{i}_{r, \psi s}-\frac{1}{T_{s}^{*}}\left|\bar{i}_{m s}\right|-j \omega_{m} \frac{T_{s}}{T_{s}^{*}}\left|\bar{i}_{m s}\right| .
$$

Substituting (22) in (20) and rewriting rotor voltage equations, 


$$
\begin{aligned}
u_{r, \psi s}= & R_{r} \bar{i}_{r, \psi s}+L_{r}^{\prime} \frac{\mathrm{d} \bar{i}_{r, \psi s}}{\mathrm{~d} t}+\frac{\Delta L^{*}}{L} \frac{\bar{u}_{s, \psi s} \bar{i}_{r, \psi s}+\bar{i}_{r, \psi s} \frac{\Delta L^{*}}{\left|\bar{i}_{m s}\right|} \frac{1}{T_{s}^{*}} \bar{i}_{r, \psi s}}{}+\frac{1}{T_{s}^{*}} \Delta L^{*} \bar{i}_{r, \psi s}-j \omega_{m s} \frac{T_{s}}{T_{s}^{*}} \Delta L^{*} \bar{i}_{r, \psi s}+\frac{L_{m}^{2}}{L_{s}} \frac{\bar{u}_{s, \psi s}}{L} \\
& +\frac{L_{m}^{2}}{L_{s}} \frac{1}{T_{s}^{*}} \bar{i}_{r, \psi s}-\frac{L_{m}^{2}}{L_{s}} \frac{1}{T_{s}^{*}}\left|\bar{i}_{m s}\right|-j \omega_{m} \frac{T_{s}}{T_{s}^{*}} \frac{L_{m}^{2}}{L_{s}}\left|\bar{i}_{m s}\right| \\
& +\left(\Delta L-\Delta L^{*}\right) \frac{\bar{u}_{s, \psi s}}{L}+\left(\Delta L-\Delta L^{*}\right) \frac{1}{T_{s}^{*}} \bar{i}_{r, \psi s} \\
& -\left(\Delta L-\Delta L^{*}\right) \frac{1}{T_{s}^{*}}\left|\bar{i}_{m s}\right|-j \omega_{m s} \frac{T_{s}}{T_{s}^{*}}\left(\Delta L-\Delta L^{*}\right)\left|\bar{i}_{m s}\right| \\
& +j\left(\omega_{m s}-\omega_{r}\right) L_{r}^{\prime} \bar{i}_{r, \psi s}+j\left(\omega_{m s}-\omega_{r}\right) \frac{L_{m}^{2}}{L_{s}}\left|\bar{i}_{m s}\right| .
\end{aligned}
$$

Since the magnetizing current space vector is oriented along the $x$-axis of the reference frame, $\bar{i}_{m r y}=0$. Rewriting rotor currents by substituting $\bar{i}_{m s y}=0$ and resolving rotor current components along $x$ and $y$ direction, rotor equations can be expressed as follows:

$$
\begin{aligned}
u_{r x}= & L_{r}^{\prime} \frac{\mathrm{d} \bar{i}_{r x}}{\mathrm{~d} t}+R_{r} i_{r x}+\frac{\Delta L^{*}}{L} \frac{\bar{u}_{s x}}{\left|\bar{i}_{m s}\right|} i_{r x}-\frac{\Delta L^{*}}{L} \frac{\bar{u}_{s y}}{\left|\bar{i}_{m s}\right|} i_{r y} \\
& -\frac{1}{T_{s}^{*}} \Delta L^{*} i_{r x}+\frac{L_{m}^{2}}{L_{s}} \frac{1}{T_{s}^{*}} i_{r x}+\left(\Delta L-\Delta L^{*}\right) \frac{1}{T_{s}^{*}} i_{r x} \\
& -\left(\omega_{m s}-\omega_{r}\right) L_{r}^{\prime} i_{r y}-\frac{L_{m}^{2}}{L_{s}} \frac{1}{T_{s}^{*}}\left|\bar{i}_{m s}\right|-\left(\Delta L-\Delta L^{*}\right) \frac{1}{T_{s}^{*}}\left|\bar{i}_{m s}\right| \\
& +\frac{\Delta L^{*}}{\left|\bar{i}_{m s}\right|} \frac{1}{T_{s}^{*}} i_{r x}^{2}-\frac{\Delta L^{*}}{\left|\bar{i}_{m s}\right|} \frac{1}{T_{s}^{*}} i_{r y}^{2}+\frac{L_{m}^{2}}{L_{s}} \frac{\bar{u}_{s x}}{L}+\left(\Delta L-\Delta L^{*}\right) \frac{\bar{u}_{s x}}{L} \\
u_{r y}= & L_{r}^{\prime} \frac{\mathrm{d} \bar{i}_{r y}}{\mathrm{~d} t}+R_{r} i_{r y}+\frac{\Delta L^{*}}{L} \frac{\bar{u}_{s x}}{\left|\bar{i}_{m s}\right|} i_{r y}+\frac{\Delta L^{*}}{L} \frac{\bar{u}_{s y}}{\left|\bar{i}_{m s}\right|} i_{r x} \\
& -\frac{1}{T_{s}^{*}} \Delta L^{*} i_{r y}+\frac{L_{m}^{2}}{L_{s}} \frac{1}{T_{s}^{*}} i_{r y}+\left(\Delta L-\Delta L^{*}\right) \frac{1}{T_{s}^{*}} i_{r y} \\
& +\frac{2 \Delta L^{*}}{\left|\bar{i}_{m s}\right|} \frac{1}{T_{s}^{*}} i_{r x} i_{r y}+\frac{L_{m}^{2}}{L_{s}} \frac{\bar{u}_{s y}}{L}+\left(\Delta L-\Delta L^{*}\right) \frac{\bar{u}_{s y}}{L} . \\
& +\left(\omega_{m s}-\omega_{r}\right) L_{r}^{\prime} i_{r x}-\omega_{m} \frac{T_{s}}{T_{s}^{*}} \frac{L_{m}^{2}}{L_{s}}\left|\bar{i}_{m s}\right| \\
T_{s}^{*} & \left(\Delta L-\Delta L^{*}\right)\left|\bar{i}_{m s}\right|+\left(\omega_{m s}-\omega_{r}\right) \frac{L_{m}^{2}}{L_{s}}\left|\bar{i}_{m s}\right| \\
& \\
&
\end{aligned}
$$

4.3. State Space Model of the DFIG. The state space model of the doubly fed induction generator expressed in terms of stator magnetizing current and rotor current can be written as follows:

$$
\begin{aligned}
& \frac{\mathrm{d} \bar{i}_{m s x}}{\mathrm{~d} t}=\frac{\bar{u}_{s x}}{L}-\frac{1}{T_{s}^{*}}\left(\bar{i}_{m s x}-\bar{i}_{r x}\right), \\
& L_{r}^{\prime} \frac{\mathrm{d} \bar{i}_{r x}}{\mathrm{~d} t}=-R_{r} i_{r x}-\frac{\Delta L^{*}}{L} \frac{\bar{u}_{s x}}{\left|\bar{i}_{m s}\right|} i_{r x}+\frac{\Delta L^{*}}{L} \frac{\bar{u}_{s y}}{\left|\bar{i}_{m s}\right|} i_{r y}+\frac{1}{T_{s}^{*}} \Delta L^{*} i_{r x} \\
& -\frac{L_{m}^{2}}{L_{s}} \frac{1}{T_{s}^{*}} i_{r x}-\left(\Delta L-\Delta L^{*}\right) \frac{1}{T_{s}^{*}} i_{r x}+\left(\omega_{m s}-\omega_{r}\right) L_{r}^{\prime} i_{r y} \\
& +\frac{L_{m}^{2}}{L_{s}} \frac{1}{T_{s}^{*}}\left|\bar{i}_{m s}\right|+\left(\Delta L-\Delta L^{*}\right) \frac{1}{T_{s}^{*}}\left|\bar{i}_{m s}\right|-\frac{\Delta L^{*}}{\left|\bar{i}_{m s}\right|} \frac{1}{T_{s}^{*}} i_{r x}^{2} \\
& +\frac{\Delta L^{*}}{\left|\bar{i}_{m s}\right|} \frac{1}{T_{s}^{*}} i_{r y}^{2}-\frac{L_{m}^{2}}{L_{s}} \frac{\bar{u}_{s x}}{L}-\left(\Delta L-\Delta L^{*}\right) \frac{\bar{u}_{s x}}{L}+u_{r x}, \\
& L_{r}^{\prime} \frac{\mathrm{d} \bar{i}_{r y}}{\mathrm{~d} t}=-R_{r} i_{r y}-\frac{\Delta L^{*}}{L} \frac{\bar{u}_{s x}}{\left|\bar{i}_{m s}\right|} i_{r y}-\frac{\Delta L^{*}}{L} \frac{\bar{u}_{s y}}{\left|\bar{i}_{m s}\right|} i_{r x}+\frac{1}{T_{s}^{*}} \Delta L^{*} i_{r y} \\
& -\frac{L_{m}^{2}}{L_{s}} \frac{1}{T_{s}^{*}} i_{r y}-\left(\Delta L-\Delta L^{*}\right) \frac{1}{T_{s}^{*}} i_{r y}-\left(\omega_{m s}-\omega_{r}\right) L_{r}^{\prime} i_{r x} \\
& +\omega_{m} \frac{T_{s}}{T_{s}^{*}} \frac{L_{m}^{2}}{L_{s}}\left|\bar{i}_{m s}\right|+\omega_{m} \frac{T_{s}}{T_{s}^{*}}\left(\Delta L-\Delta L^{*}\right)\left|\bar{i}_{m s}\right| \\
& -\left(\omega_{m s}-\omega_{r}\right) \frac{L_{m}^{2}}{L_{s}}\left|\bar{i}_{m s}\right|-\frac{2 \Delta L^{*}}{\left|\bar{i}_{m s}\right|} \frac{1}{T_{s}^{*}} i_{r x} i_{r y}-\frac{L_{m}^{2}}{L_{s}} \frac{\bar{u}_{s y}}{L} \\
& -\left(\Delta L-\Delta L^{*}\right) \frac{\bar{u}_{s y}}{L}+u_{r y} .
\end{aligned}
$$

\section{Input-Output Feedback Linearization Control of the DFIG}

The outputs of the DFIG to be controlled are active power output $\left(P_{s}\right)$ which depends on rotor speed $\omega_{r}$ and reactive power output $\left(Q_{s}\right)$. The two outputs are chosen as follows:

$$
\begin{aligned}
& y_{1}=\omega_{r}, \\
& y_{2}=Q_{s} .
\end{aligned}
$$
by

The first and second derivatives of first output $\omega_{r}$ is given

$$
\begin{aligned}
& \dot{y}_{1}=\frac{\mathrm{d} \omega_{r}}{\mathrm{~d} t}=-\frac{3}{2} \frac{p^{2}}{J} \frac{L_{m}^{2}}{L_{s}} i_{m s} i_{r y}-\frac{p}{J} T_{L}, \\
& \ddot{y}_{1}=-\frac{3}{2} \frac{p^{2}}{J} \frac{L_{m}^{2}}{L_{s}}\left[i_{m s} \frac{\mathrm{d} i_{r y}}{\mathrm{~d} t}+i_{r y} \frac{\mathrm{d} i_{m s}}{\mathrm{~d} t}\right] .
\end{aligned}
$$

Substituting for $\mathrm{d} i_{r y} / \mathrm{d} t$ and $\mathrm{d} i_{m s} / \mathrm{d} t$, 


$$
\begin{aligned}
\ddot{y}_{1}= & -\frac{3}{2} \frac{p^{2}}{J} \frac{L_{m}^{2}}{L_{s}} \frac{i_{m s}}{\sigma L_{r}}\left[-R_{r} i_{r y}-\frac{\Delta L^{*}}{L} \frac{\bar{u}_{s x}}{\left|\bar{i}_{m s}\right|} i_{r y}-\frac{\Delta L^{*}}{L} \frac{\bar{u}_{s y}}{\left|\bar{i}_{m s}\right|} i_{r x}\right. \\
& +\frac{1}{T_{s}^{*}} \Delta L^{*} i_{r y}-\frac{L_{m}^{2}}{L_{s}} \frac{1}{T_{s}^{*}} i_{r y}-\left(\Delta L-\Delta L^{*}\right) \frac{1}{T_{s}^{*}} i_{r y} \\
& -\left(\omega_{m s}-\omega_{r}\right) L_{r}^{\prime} i_{r x}+\omega_{m} \frac{T_{s}}{T_{s}^{*}} \frac{L_{m}^{2}}{L_{s}}\left|\bar{i}_{m s}\right|+\omega_{m} \frac{T_{s}}{T_{s}^{*}}(\Delta L \\
& \left.-\Delta L^{*}\right)\left|\bar{i}_{m s}\right|-\left(\omega_{m s}-\omega_{r}\right) \frac{L_{m}^{2}}{L_{s}}\left|\bar{i}_{m s}\right|-\frac{2 \Delta L^{*}}{\left|\bar{i}_{m s}\right|} \frac{1}{T_{s}^{*}} i_{r x} i_{r y} \\
& \left.-\frac{L_{m}^{2}}{L_{s}} \frac{\bar{u}_{s y}}{L}-\left(\Delta L-\Delta L^{*}\right) \frac{\bar{u}_{s y}}{L}+u_{r y}\right]-\frac{3}{2} \frac{p^{2}}{J} \frac{L_{m}^{2}}{L_{s}} i_{r y} \\
& \cdot\left[\frac{R_{s}}{L_{s}}\left(i_{r x}-i_{m s}\right)+\frac{u_{s x}}{L}\right] .
\end{aligned}
$$

The input voltage appears $u_{r y}$ appears in the second derivative $\ddot{y}_{1}$.

The second output to be differentiated is stator reactive power, $Q_{s}=(3 / 2)\left(L_{m} / L_{s}\right) u_{s y}\left(i_{m s}-i_{r y}\right)$ :

$$
\begin{aligned}
\dot{y}_{2}= & \frac{3}{2} \frac{L_{m}}{L_{s}} u_{s y}\left(\frac{\mathrm{d} i_{m s}}{\mathrm{~d} t}-\frac{\mathrm{d} i_{r y}}{\mathrm{~d} t}\right), \\
\dot{y}_{2}= & \frac{3}{2} \frac{L_{m}}{L_{s}} u_{s y}\left[\frac{R_{s}}{L_{s}}\left(i_{r x}-i_{m s}\right)+\frac{u_{s x}}{L}\right]-\frac{3}{2} \frac{L_{m}}{L_{s}} \frac{1}{\sigma L_{r}} u_{s y} \\
& \cdot\left[-R_{r} i_{r x}-\frac{\Delta L^{*}}{L} \frac{\bar{u}_{s x}}{\left|\bar{i}_{m s}\right|} i_{r x}+\frac{\Delta L^{*}}{L} \frac{\bar{u}_{s y}}{\left|\bar{i}_{m s}\right|} i_{r y}+\frac{1}{T_{s}^{*}} \Delta L^{*} i_{r x}\right. \\
& -\frac{L_{m}^{2}}{L_{s}} \frac{1}{T_{s}^{*}} i_{r x}-\left(\Delta L-\Delta L^{*}\right) \frac{1}{T_{s}^{*}} i_{r x}+\left(\omega_{m s}-\omega_{r}\right) L_{r}^{\prime} i_{r y} \\
& +\frac{L_{m}^{2}}{L_{s}} \frac{1}{T_{s}^{*}}\left|\bar{i}_{m s}\right|+\left(\Delta L-\Delta L^{*}\right) \frac{1}{T_{s}^{*}}\left|\bar{i}_{m s}\right|-\frac{\Delta L^{*}}{\left|\bar{i}_{m s}\right|} \frac{1}{T_{s}^{*}} i_{r x}^{2} \\
& \left.+\frac{\Delta L^{*}}{\left|\bar{i}_{m s}\right|} \frac{1}{T_{s}^{*}} i_{r y}^{2}-\frac{L_{m}^{2}}{L_{s}} \frac{\bar{u}_{s x}}{L}-\left(\Delta L-\Delta L^{*}\right) \frac{\bar{u}_{s x}}{L}+u_{r x}\right] .
\end{aligned}
$$

The input voltage $u_{r x}$ appears in the first derivative $\dot{y}_{2}$ :

$$
\dot{Y}=A(X)+E(X)\left[\begin{array}{l}
u_{r x} \\
u_{r y}
\end{array}\right] .
$$

The input-output feedback linearization is performed by defining new control inputs $v_{1}$ and $v_{2}$ :

$$
\begin{aligned}
& {\left[\begin{array}{l}
v_{1} \\
v_{2}
\end{array}\right]=A(X)+E(X)\left[\begin{array}{l}
u_{r x} \\
u_{r y}
\end{array}\right],} \\
& {\left[\begin{array}{l}
u_{r x} \\
u_{r y}
\end{array}\right]=E^{-1}(X)\left[-A(X)+\left[\begin{array}{l}
v_{1} \\
v_{2}
\end{array}\right]\right] .}
\end{aligned}
$$

The reference active power $P_{s}^{\text {ref }}$ is determined by the maximum power tracking control scheme of the wind turbine according to the speed of the wind, and the demanded reactive power $Q_{s}^{\text {ref }}$ is determined by the grid requirements. The desired reference powers $\omega_{r}^{\text {ref }}$ and $Q_{s}^{\text {ref }}$ are achieved by employing proportional controllers. Hence, the new input $V$ is calculated by

$$
\begin{aligned}
& v_{1}=\ddot{y}_{1}^{d}-k_{11}\left(\dot{y}_{1}-\dot{y}_{1}^{d}\right)-k_{12}\left(y_{1}-y_{1}^{d}\right), \\
& v_{2}=\dot{y}_{2}^{d}-k_{21}\left(y_{2}-y_{2}^{d}\right) .
\end{aligned}
$$

$e_{1}$ is the error between the reference and the measured active power, and $e_{2}$ is that of the reactive power:

$$
\begin{aligned}
& e_{1}=y_{1}^{*}-y_{1}, \\
& e_{2}=y_{2}^{*}-y_{2} .
\end{aligned}
$$

The parameters of the proportional controller can be selected by applying the Routh stability criterion and thereby leading the system stable:

$$
\begin{aligned}
\ddot{e}_{1}+k_{p 11} \dot{e}_{1}+k_{p 12} e_{1} & =0 \\
\dot{e}_{2}+k_{21} e_{2} & =0 .
\end{aligned}
$$

\section{Feedback Linearization Control Scheme}

The block diagram of the feedback control technique is as shown in Figure (4). The controller receives reference and estimated active powers and reactive powers as input and provides at output the direct and quadrature components of rotor voltages in the stator flux-oriented reference frame.

The schematic diagram of the overall feedback linearization control scheme of the doubly fed induction generator is drawn in Figure 5. As the stator magnetizing current cannot be measured directly, a flux model [30] is used to estimate the stator magnetizing current. The input signals $v_{1}$ and $v_{2}$ are chosen such that power variables track their reference values. Then, input rotor voltage components $u_{r x}$ and $u_{r y}$ are obtained by feedback using equation (32).

\section{Simulation Results}

The simulations have been performed for the machine of parameter $\left(2 \mathrm{MW}, 690 \mathrm{~V}, 2\right.$ poles, $R_{s}=2.6 \mathrm{~m} \Omega$, $R_{r}=2.9 \mathrm{~m} \Omega$, and $L_{l r}, L_{l s}=0.087 \mathrm{mH}$ ) to test the performance of the feedback linearization control [1]. The block diagram used for simulation is shown in Figure 5. The simulations are conducted for an electrical speed reference, $\omega_{r}=282.73 \mathrm{rad} / \mathrm{sec}$, which is 0.9 times the electrical angular frequency corresponding to synchronous speed and for stator reactive power reference, $Q_{s}=0$. Unlike, the singly excited induction generator, the DFIG has the advantage to operate at subsynchronous speed also. As the rotor of the DFIG is connected to the grid through back to back converter, the rotor of the DFIG can supply reactive power to the grid. Hence, the reactive power supplied or absorbed by stator to and from the grid $Q_{s}$ is taken as zero. The state variables selected for the formulation of the feedback linearization control law are stator magnetizing current and rotor currents. 


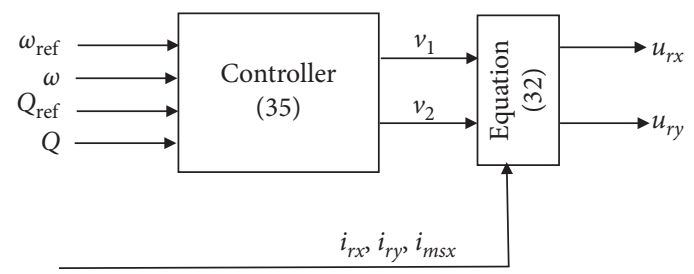

FIGURE 4

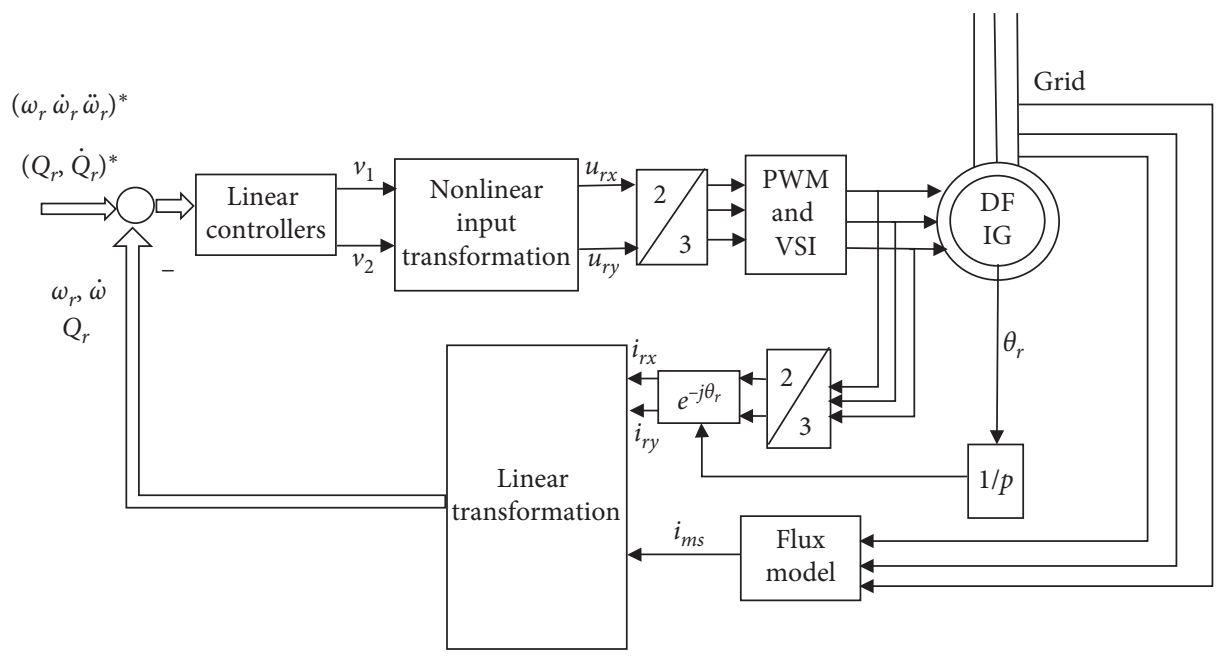

FiguRE 5

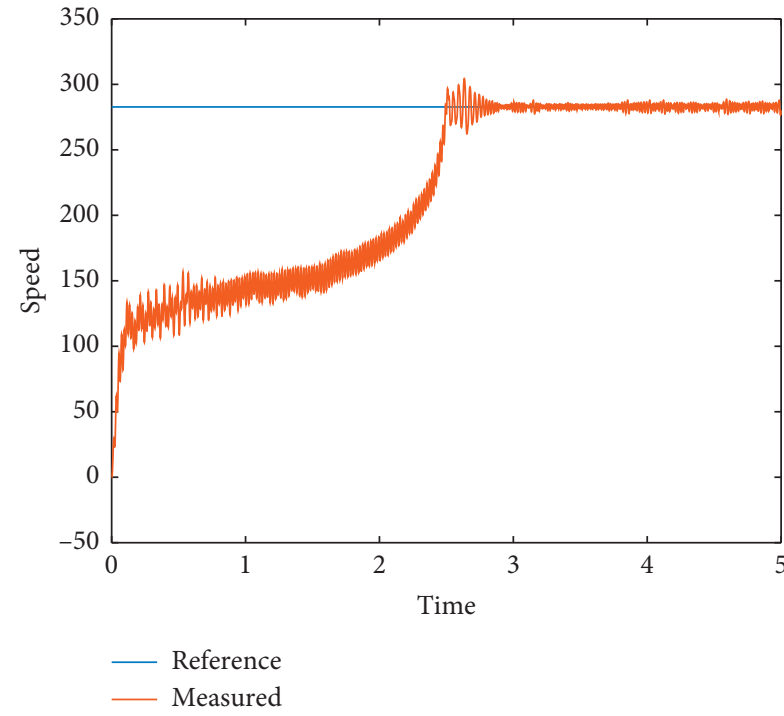

(a)

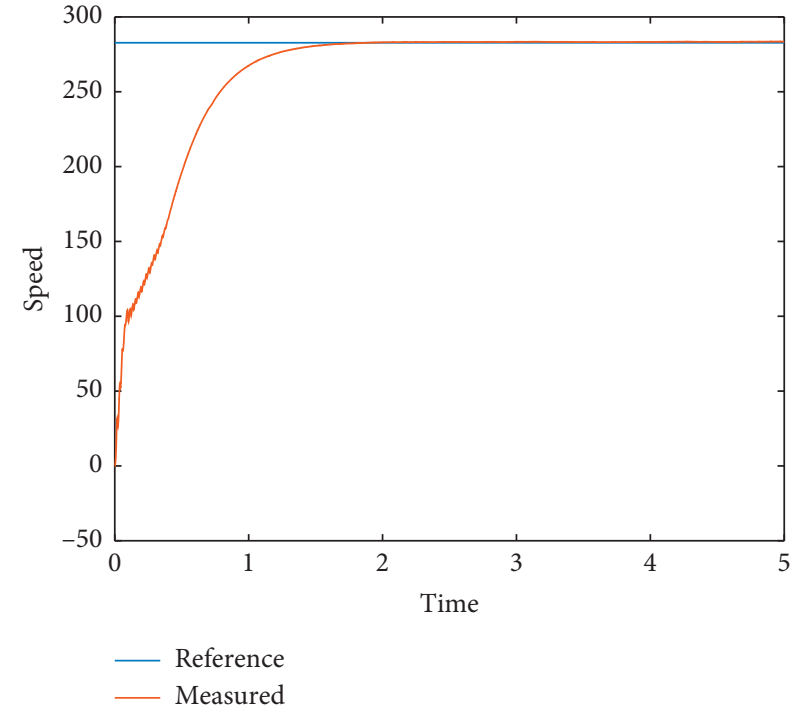

(b)

FIGURE 6: Simulation results for angular speed (a) without saturation and (b) with saturation.

The results of feedback linearization control without saturation and with saturation were obtained. The results of simulation are shown in Figures 6-7. Figures 6(a) and 6(b) show the reference and measured speed for $\omega_{r, \text { ref }}=282.73 \mathrm{rad} / \mathrm{sec}$, which is 0.9 times the electrical angular frequency corresponding to synchronous speed. An analysis of the results shows that rise time for feedback linearization with saturation is much less when compared to feedback linearization without saturation and the tracking error is considerably small when magnetic saturation is considered.

The rise time obtained with feedback linearization with saturation is about $1.5 \mathrm{~s}$ which is lower than feedback linearization without saturation, equal to $2.3 \mathrm{~s}$. Figures $7(\mathrm{a})$ and $7(\mathrm{~b})$ show the reactive power reference and measured reactive 


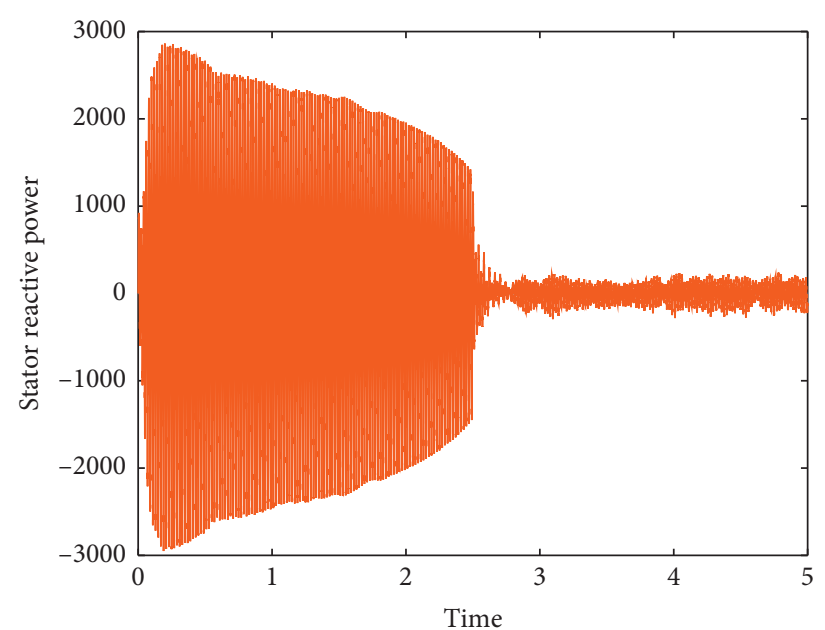

- Reference

— Measured

(a)

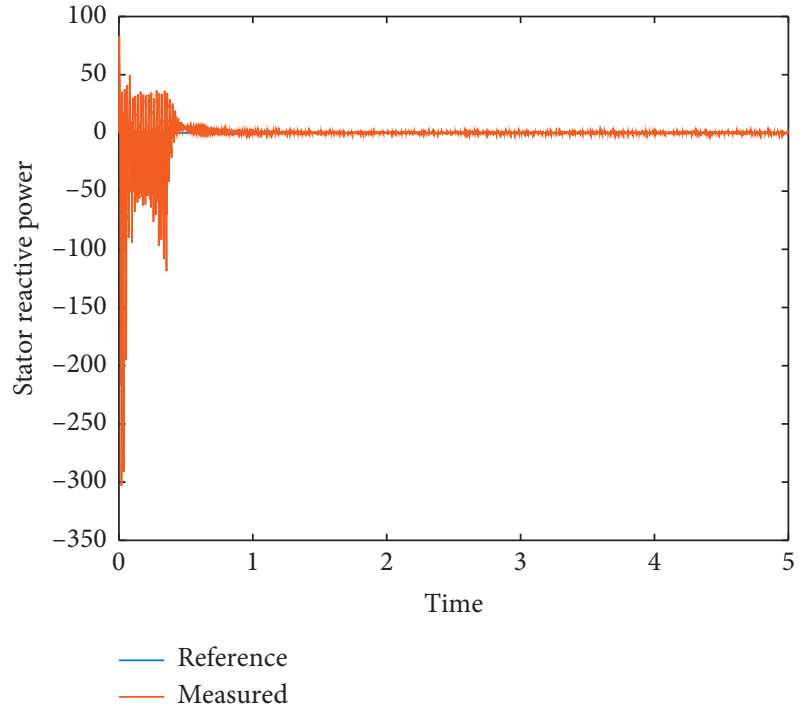

(b)

FIGURE 7: Simulation results for stator reactive power (a) without saturation and (b) with saturation.

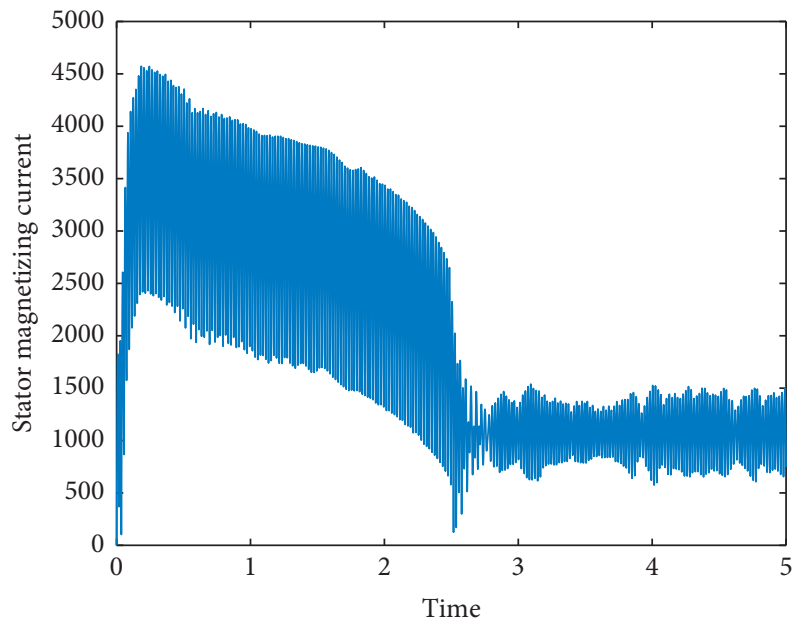

(a)

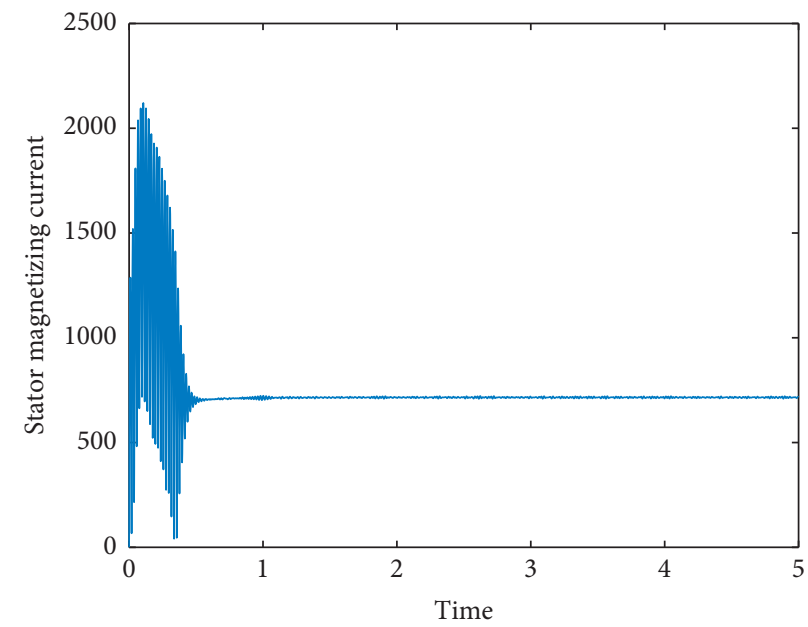

(b)

FIGURE 8: Simulation results for stator magnetizing current (a) without saturation and (b) with saturation.

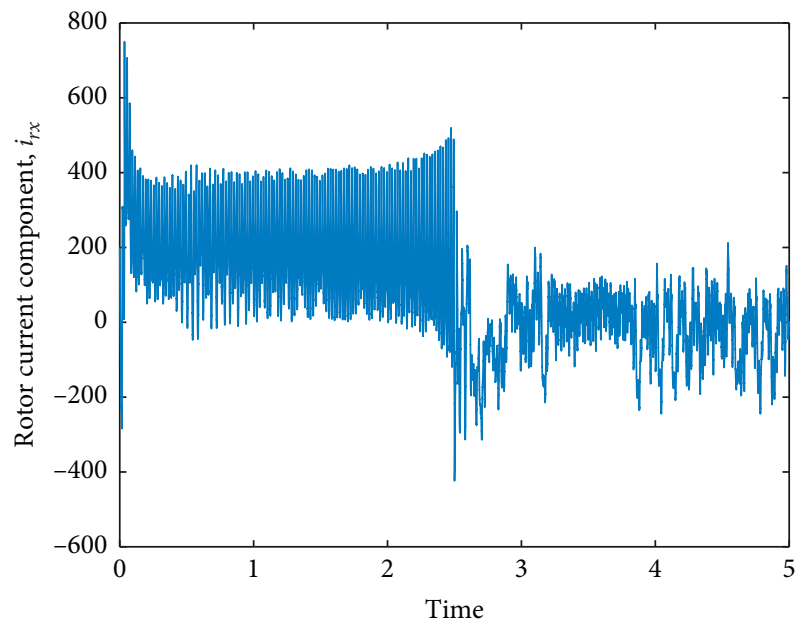

(a)

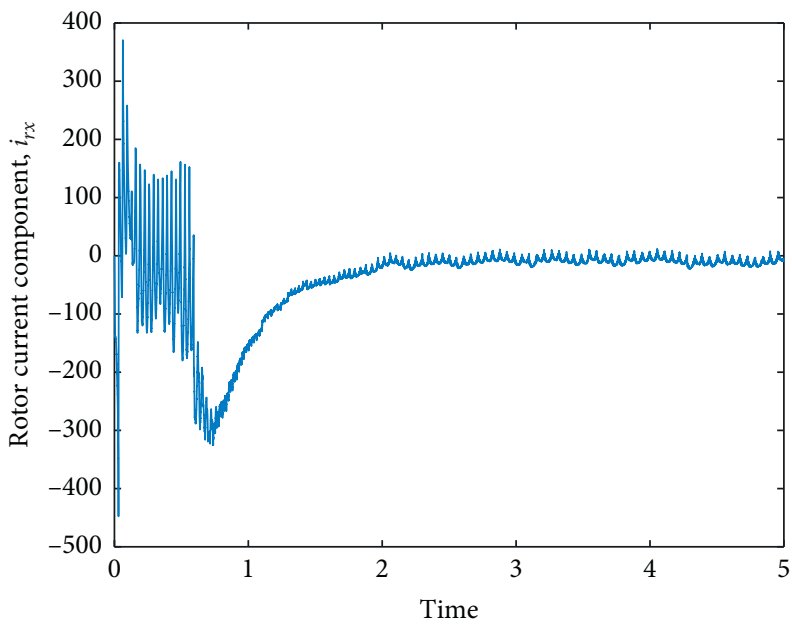

(b)

Figure 9: Continued. 


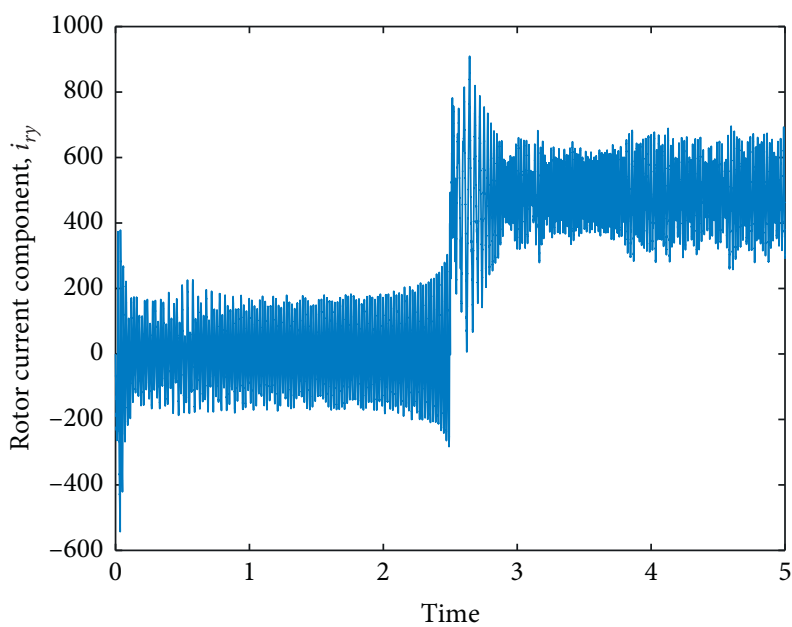

(c)

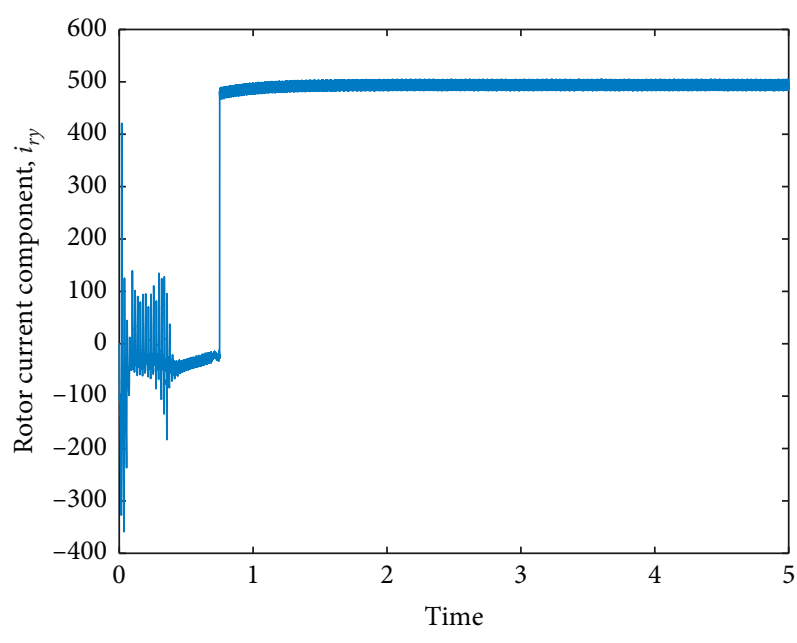

(d)

FIgURE 9: Simulation results for rotor current components: (a) rotor $x$-axis current component without saturation, (b) rotor $x$-axis current component with saturation (c) rotor $y$-axis current component without saturation, and (d) rotor $y$-axis current component with saturation.

power for feedback linearization without saturation and feedback linearization with saturation. It is found that although two cases have almost same rise time, the feedback linearization control with saturation produces smooth trajectory.

Figures $8(\mathrm{a})$ and $8(\mathrm{~b})$ show the corresponding stator magnetizing currents obtained for both saturated and unsaturated case. It is found that magnetizing current required for feedback linearization with saturation is higher compared to the feedback linearization without saturation. The waveforms of the corresponding direct and quadrature rotor current components, as shown in Figure 9, highlight the better dynamic performance achieved with the feedback linearization with saturation. This improved performance is due to the correct knowledge of the model parameters adopted while formulating the control law.

\section{Conclusion}

This paper presents the feedback linearization control method for the doubly fed induction generator considering the magnetic saturation. The corresponding feedback linearization technique was framed from a new formulation of the dynamic model of the doubly fed induction generator, taking into account of the magnetic saturation. The inclusion of magnetic saturation in the doubly fed induction generator model increases its accuracy and results in a more efficient and reliable synthesis of the control algorithm. This is mainly due to the precisely observed value of the stator flux-linkage. Computer studies confirm that the proposed feedback linearization control method have better dynamic performance.

\section{Data Availability}

The data used to support the findings of this study are included within the supplementary information file.

\section{Conflicts of Interest}

The authors declare that they have no conflicts of interest.

\section{Supplementary Materials}

Machine parameters used for simulation, taken from [1]. (Supplementary Materials)

\section{References}

[1] G. Abad, J. Lopez, M. A. Rodriguez, L. Marroyo, and G. Iwanski, Doubly Fed Induction Machine Modeling and Control for Wind Energy Generation Applications, Wiley, Hoboken, NJ, USA, 2011.

[2] S. Muller, M. Deicke, and R. W. De Doncker, "Doubly fed induction generator systems for wind turbines," IEEE Industry Applications Magazine, vol. 8, pp. 26-33, 2002.

[3] G. Rigatos, Intelligent Renewable Energy Systems: Modelling and Control, Springer, Switzerland, 2016.

[4] M. Alrifai, M. Zribi, and M. Rayan, "Feedback linearization controller for a wind energy power system," Energies, vol. 9, no. 10, p. 771, 2016.

[5] H. K. Khalil, Nonlinear Systems, vol. 3, Prentice-Hall, Upper Saddle River, NJ, USA, 2002.

[6] A. Isidori, Nonlinear Control Systems, Springer, London, UK, 1995.

[7] M. Pucci, "Non-linear control techniques of LIMs," in Advanced Linear Machines and Drive Systems, pp. 227-280, Springer, Singapore, 2019.

[8] L. Gao and D. Wang, "Input-to-state stability and integral input-to-state stability for impulsive switched systems with time-delay under asynchronous switching," Nonlinear Analysis: Hybrid Systems, vol. 20, pp. 55-71, 2016.

[9] X. Yan, X. Song, and X. Wang, "Global output-feedback stabilization for nonlinear time-delay systems with unknown control coefficients," International Journal of Control, Automation and Systems, vol. 16, no. 4, pp. 1550-1557, 2018.

[10] F. Beltran-Carbajal, I. Lopez-Garcia, J. C. Rosas-Caro, V. M. Sanchez-Huerta, A. Favela-Contreras, and A. Valderrabano-Gonzalez, "Output feedback dynamic tracking excitation control of synchronous generators," IET Generation, Transmission \& Distribution, vol. 10, no. 12, pp. 3041-3049, 2016. 
[11] M. A. Mahmud, M. J. Hossain, H. R. Pota, and A. M. T. Oo, "Robust partial feedback linearizing excitation controller design for multimachine power systems," IEEE Transactions on Power Systems, vol. 32, no. 1, pp. 3-16, 2017.

[12] T. F. Orchi, T. K. Roy, M. A. Mahmud, and A. M. T. Oo, "Feedback linearizing model predictive excitation controller design for multimachine power systems," IEEE Access, vol. 6, pp. 2310-2319, 2018.

[13] S. M. Mohiuddin, M. A. Mahmud, A. M. O. Haruni, and H. R. Pota, "Design and implementation of partial feedback linearizing controller for grid-connected fuel cell systems," International Journal of Electrical Power \& Energy Systems, vol. 93, pp. 414-425, 2017.

[14] T. F. Orchi, M. A. Mahmud, and A. M. Oo, "Partial feedback linearizing model predictive controllers for multiple photovoltaic units connected to grids through a point of common coupling," Electronics, vol. 7, no. 9, 2018.

[15] L. Callegaro, M. Ciobotaru, D. J. Pagano, and J. E. Fletcher, "Feedback linearization control in photovoltaic module integrated converters," IEEE Transactions on Power Electronics, vol. 34, no. 7, pp. 6876-6889, 2019.

[16] A. Merabet, L. Labib, A. M. Y. M. Ghias, C. Ghenai, and T. Salameh, "Robust feedback linearizing control with sliding mode compensation for a grid-connected photovoltaic inverter system under unbalanced grid voltages," IEEE Journal of Photovoltaics, vol. 7, no. 3, pp. 828-838, 2017.

[17] A. De Luca and G. Ulivi, "Design of an exact nonlinear controller for induction motors," IEEE Transactions on Automatic Control, vol. 34, no. 12, pp. 1304-1307, 1989.

[18] D.-I. Kim, I.-J. Ha, and M.-S. Ko, "Control of induction motors via feedback linearization with input-output decoupling," International Journal of Control, vol. 51, no. 4, pp. 863-883, 1990.

[19] G. F. Bellini and F. Tosti, "Linearized model of induction motor drives via nonlinear state-feedback decoupling," in Proceedings of the 4th European Conference on Power Electronics and Applicatin, pp. 3036-3041, Frienze, Italy, September 1991.

[20] A. Ammar, A. Kheldoun, B. Metidji, T. Amied, and Y. Azzoug, "Feedback linearization based sensorless direct torque control using stator flux MRAS-sliding mode observer for induction motor drive," ISA Transactions, 2019, In press.

[21] G. S. Kaloi, J. Wang, and M. H. Baloch, "Active and reactive power control of the doubly fed induction generator based on wind energy conversion system," Energy Reports, vol. 2, no. 2, pp. 194-200, 2016.

[22] A. L. Nemmour and R. Abdessemed, "The input-output linearizing control scheme of the doubly-fed induction machine as a wind power generation," Wind Engineering, vol. 32, no. 3, pp. 285-297, 2018.

[23] Y. Sun, S. Yan, B. Cai, and Y. Wu, "Maximum power point tracking of DFIG with DC-based converter system using coordinated feedback linearization control," Mathematical Problems in Engineering, vol. 2018, Article ID 9642123, 12 pages, 2018.

[24] P. Li, L. Xiong, F. Wu, M. Ma, and J. Wang, "Sliding mode controller based on feedback linearization for damping of sub-synchronous control interaction in DFIG-based wind power plants," International Journal of Electrical Power \& Energy Systems, vol. 107, pp. 239-250, 2019.

[25] G. Kaloi, M. Baloch, M. Kumar et al., "An LVRT scheme for grid connected DFIG based WECS using state feedback linearization control technique," Electronics, vol. 8, no. 7, p. 777, 2019.
[26] M. Tarbouchi and H. Le Huy, "Nonlinear control of an induction motor in magnetic saturation," in Proceedings of the Conference Record of 1998 IEEE Industry Applications Conference. Thirty-Third IAS Annual Meeting (Cat. No.98CH36242), pp. 648-653, St. Louis, MO, USA, October 1998.

[27] D. Dolinar, P. Ljušev, and G. Tumberger, "Input-output linearising tracking control of an induction motor including magnetic saturation effects," IEE Proceedings-Electric Power Applications, vol. 150, no. 6, pp. 703-711, 2003.

[28] H. A. A. Fattah, "Input-output linearization of induction motors with magnetic saturation," in Proceedings of the 2000 American Control Conference, pp. 600-604, Chicago, IL, USA, June 2000.

[29] A. Accetta, F. Alonge, M. Cirrincione, M. Pucci, and A. Sferlazza, "Feedback linearizing control of induction motor considering magnetic saturation effects," IEEE Transactions on Industry Applications, vol. 52, no. 6, pp. 4843-4854, 2016.

[30] P. Vas, Sensorless Vector and Direct Torque Control, Oxford University Press, Oxford, UK, 1998. 